\title{
Contribution of matrix vesicles and alkaline phosphatase to ectopic bone formation
}

P. Ciancaglini ${ }^{1}$, A.M.S. Simão ${ }^{1}$, F.L. Camolezi ${ }^{1}$, J.L. Millán ${ }^{2}$ and J.M. Pizauro ${ }^{3}$

\author{
'Departamento de Química, Faculdade de Filosofia, \\ Ciências e Letras de Ribeirão Preto, Universidade de São Paulo, \\ Ribeirão Preto, SP, Brasil \\ 2The Burnham Institute, La Jolla, CA, USA \\ ${ }^{3}$ Departamento de Tecnologia, Faculdade de Ciências Agrárias e Veterinárias de \\ Jaboticabal, Universidade Estadual Paulista, Jaboticabal, SP, Brasil
}

\section{Correspondence \\ P. Ciancaglini \\ Departamento de Química \\ Faculdade de Filosofia, Ciências \\ e Letras de Ribeirão Preto, USP \\ 14040-901 Ribeirão Preto, SP \\ Brasil \\ Fax: +55-16-36024838 \\ E-mail: pietro@ffclrp.usp.br}

Research supported in part by FAPESP and CNPq, and by grants DE 12889 and AR 47908 from the National Institutes of Health, USA.

Received June 17, 2005

Accepted January 13, 2006

\begin{abstract}
Endochondral calcification involves the participation of matrix vesicles (MVs), but it remains unclear whether calcification ectopically induced by implants of demineralized bone matrix also proceeds via MVs. Ectopic bone formation was induced by implanting rat demineralized diaphyseal bone matrix into the dorsal subcutaneous tissue of Wistar rats and was examined histologically and biochemically. Budding of MVs from chondrocytes was observed to serve as nucleation sites for mineralization during induced ectopic osteogenesis, presenting a diameter with Gaussian distribution with a median of $306 \pm 103$ $\mathrm{nm}$. While the role of tissue-nonspecific alkaline phosphatase (TNAP) during mineralization involves hydrolysis of inorganic pyrophosphate $\left(\mathrm{PP}_{\mathrm{i}}\right)$, it is unclear how the microenvironment of MV may affect the ability of TNAP to hydrolyze the variety of substrates present at sites of mineralization. We show that the implants contain high levels of TNAP capable of hydrolyzing p-nitrophenylphosphate (pNPP), ATP and $\mathrm{PP}_{\mathrm{i}}$. The catalytic properties of glycosyl phosphatidylinositol-anchored, polidocanol-solubilized and phosphatidylinositol-specific phospholipase C-released TNAP were compared using pNPP, $\mathrm{ATP}$ and $\mathrm{PP}_{\mathrm{i}}$ as substrates. While the enzymatic efficiency $\left(k_{\text {cat }} / K_{\mathrm{m}}\right)$ remained comparable between polidocanol-solubilized and membrane-bound TNAP for all three substrates, the $k_{\mathrm{cat}} / K_{\mathrm{m}}$ for the phosphatidylinositol-specific phospholipase C-solubilized enzyme increased approximately 108-, 56-, and 556-fold for pNPP, ATP and $\mathrm{PP}_{\mathrm{i}}$, respectively, compared to the membrane-bound enzyme. Our data are consistent with the involvement of MVs during ectopic calcification and also suggest that the location of TNAP on the membrane of MVs may play a role in determining substrate selectivity in this micro-compartment.
\end{abstract}

Key words

- Matrix vesicles

- Endochondral ossification

- Osseous plate

- Alkaline phosphatase

- Ectopic mineralization

- Calcification 


\section{Introduction}

Biological calcification is a tightly regulated process in which different types of tissues, cells, organelles, and biomolecules participate in the coordination and regulation of metabolic events involved in accumulating calcium phosphate (1-7).

Bone formation can be reproduced experimentally by the subcutaneous implantation of demineralized bone matrix, a procedure that leads to the sequential development of cartilage and bone $(8,9)$. The ectopic implantation of bone morphogenetic proteins (10) also leads to osteogenesis but by a mechanism that is unclear. Elucidating the molecular mechanisms controlling ectopic bone formation is of paramount interest because understanding these mechanisms will enable the partial or de novo reconstruction of bone tissue (11) and contribute to the establishment of therapeutic strategies for bone diseases.

We have studied ectopic bone formation, including some of the enzymes $(9,12-14)$ and lipids present in membranes of cells and/or organelles associated with this process $(15,16)$. There is good evidence that endochondral calcification involves the participations of matrix vesicles (MVs) $(7,17$, 18 ), but it is not clear whether calcification of ectopically implanted demineralized bone matrix also proceeds via MVs. According to several investigators, these extracellular organelles capable of mineral accumulation bud by exocytosis from the plasma membrane and serve as the site of primary mineralization in the matrix of bone, cartilage and dentin (4,7,17-22).

Electron microscope studies have indicated that biological calcification occurs in the MVs in two steps, the first related to the initial deposition of hydroxyapatite within the lumen of the MVs and the second to the propagation of mineral outside the vesicles $(2-4,18)$. Tissue-nonspecific alkaline phosphatase (TNAP) has been shown to be highly enriched in MVs $(17,18)$. TNAP's function in bone mainly relates to its ability to hydrolyze inorganic pyrophosphate $\left(\mathrm{PP}_{\mathrm{i}}\right)$, a potent mineralization inhibitor, while simultaneously producing $\mathrm{P}_{\mathrm{i}}$, which as a byproduct is available for deposition as hydroxyapatite $(23,24)$. Studies on MVs isolated from hypophosphatasia patients (25) or from knockout mice deficient in TNAP (26) have indicated that the first steps of mineralization remain intact in the MVs, while it is the propagation step that is severely affected in the absence of TNAP.

In the present study, we demonstrate the presence of functional MVs in the initial stages of ectopic mineralization caused by subcutaneous implantation of decalcified bone matrix. We also show that the kinetic properties of TNAP vary greatly in the presence or absence of diacylglycerol or other membrane components, suggesting that its location on MVs during mineralization may be a factor that contributes to establishing substrate specificity.

\section{Material and Methods}

\section{Material}

All aqueous solutions were made using Millipore (Bedford, MA, USA) MilliQ ultra-pure apyrogenic water. Bovine serum albumin, Tris hydroxymethyl amino methane (Tris), 2-amino-2-methyl-propan-1-ol (AMPOL), trichloroacetic acid, N-(2-hydroxyethyl) piperazine-N'-ethenesulfonic acid, adenosine 5'-triphosphate disodium salt (ATP), sodium dodecylsulfate, p-nitrophenylphosphate (pNPP), and polyoxyethylene 9 lauryl ether $\left(\mathrm{C}_{12} \mathrm{E}_{9}\right.$ - polidocanol $)$ were from Sigma (St. Louis, MO, USA). Analytical grade reagents were used without further purification.

\section{Preparation of rat osseous plate}

Adult Wistar rats of both sexes, weighing 
$350-400 \mathrm{~g}$, were killed by decapitation and the muscle-free thigh bones were removed and demineralized according to Reddi and Huggins (8). Briefly, diaphyseal bones were dehydrated and grounded in 0.125 to $0.175 \mathrm{~mm}$ fragments, treated with $0.5 \mathrm{M} \mathrm{HCl}$ in a proportion of $25 \mathrm{mM} \mathrm{HCl} / \mathrm{g}$ bone, with constant stirring and $100 \mathrm{~mA}$ of alternating current for $3 \mathrm{~h}$ at $25^{\circ} \mathrm{C}$. Finally, the remaining bone matrix was exhaustively washed using distilled water and newly dehydrated. Ten to twenty milligrams of rat demineralized diaphyseal bone matrix was introduced through a small incision in the dorsal subcutaneous tissue of anesthetized young male Wistar rats (50-60 g). Fourteen days after implantation (the period required for the development of maximal alkaline phosphatase activity), the newly formed plate was removed, rinsed in ice-cold $0.9 \%(\mathrm{w} / \mathrm{v}) \mathrm{NaCl}$, and used for microscopical examination and for alkaline phosphatase extraction (15).

\section{Electron microscopy}

The growth plate obtained after 14 days of induction was sectioned $(1 \mu \mathrm{m})$ and incubated in $0.1 \mathrm{M}$ phosphate buffer, $\mathrm{pH} 7.3$, containing $3 \%(\mathrm{w} / \mathrm{v})$ glutaraldehyde for $1 \mathrm{~h}$, followed by incubation with $1 \%(\mathrm{w} / \mathrm{v})$ osmium solution prepared in the same buffer. After $1 \mathrm{~h}$, the sample was washed in $0.1 \mathrm{M}$ sodium phosphate buffer, $\mathrm{pH} 7.3$, centrifuged and dehydrated with acetone/water mixtures of increasing acetone concentration and the final dehydration was accomplished by 3 washes with $100 \%$ acetone for $10 \mathrm{~min}$. Finally, the pellet was embedded in (1:1) araldite resin at $37^{\circ} \mathrm{C}$ for $48 \mathrm{~h}$ and in pure araldite for $72 \mathrm{~h}$ at $60^{\circ} \mathrm{C}$. Thin sections were cut using a microtome and stained with $1 \%(\mathrm{w} / \mathrm{v})$ Toluidine blue and ultrafine sections $(0.5 \mu \mathrm{m})$ were mounted on copper gilder grids (200 mesh). Finally, they were stained with $4 \%$ (w/v) uranyl acetate, $\mathrm{pH} 12$, for 10 min followed by $0.3 \%(\mathrm{w} / \mathrm{v})$ lead citrate, $\mathrm{pH}$ 12, for $10 \mathrm{~min}$. The sample was examined using a Philips (Model 208; Prague, Czecho- slovakia) transmission electron microscope.

\section{Preparation of rat osseous plate alkaline phosphatase}

An osseous plate membrane fraction rich in alkaline phosphatase, polidocanol-solubilized and phosphatidylinositol-specific phospholipase C (PIPLC)-released alkaline phosphatase was prepared as described by Camolezi et al. (15). Briefly, 14 days after implantation, the growth plate formed was removed, rinsed in ice-cold $0.9 \%(\mathrm{w} / \mathrm{v}) \mathrm{NaCl}$ and homogenized with $10 \mathrm{mM}$ Tris/ $\mathrm{HCl}$ buffer, $\mathrm{pH} 7.5$, containing $0.15 \mathrm{M} \mathrm{NaCl}(3 \mathrm{~mL}$ buffer/g osseous plate) in a high-speed shearing homogenizer, for $2 \mathrm{~min}$. The homogenate (crude extract enzyme) was centrifuged at $15,000 \mathrm{~g}$ for $20 \mathrm{~min}$ and the supernatant was dialysed overnight, at $4^{\circ} \mathrm{C}$, against 5 $\mathrm{mM}$ Tris/ $\mathrm{HCl}$ buffer, $\mathrm{pH} 7.5$, containing 2 $\mathrm{mM} \mathrm{MgCl}$ and $0.15 \mathrm{M} \mathrm{NaCl}$. The dialysed homogenate was centrifuged for $1 \mathrm{~h}$ at $160,000 \mathrm{~g}$. The pellet, corresponding to the membrane-bound enzyme was resuspended in $5 \mathrm{mM}$ Tris/HCl buffer, $\mathrm{pH} 7.5$, containing $2 \mathrm{mM} \mathrm{MgCl}$. Samples of membrane fraction $(0.2 \mathrm{mg} / \mathrm{mL})$ were treated with $1 \%$ polidocanol for $1 \mathrm{~h}$ with constant stirring at $25^{\circ} \mathrm{C}$ or aliquots $(2 \mathrm{mg} / \mathrm{mL})$ were incubated with 0.1 U PIPLC from $B$. thuringiensis for $1 \mathrm{~h}$ under constant stirring at $25^{\circ} \mathrm{C}$. Both samples were centrifuged at $100,000 \mathrm{~g}$ for 1 $\mathrm{h}$, at $4^{\circ} \mathrm{C}$. The supernatants were the source of solubilized or enzymatically released alkaline phosphatase, respectively.

\section{Enzymatic activity measurements}

p-Nitrophenylphosphatase (pNPPase), adenosine-5'-triphosphatase (ATPase) and pyrophosphatase ( $\mathrm{PP}_{\mathrm{i}}$ ase) activities were assayed as described by Camolezi et al. (15). Briefly, pNPPase activity was assayed discontinuously at $37^{\circ} \mathrm{C}$ in a Spectronic (Genesys 2 ) spectrophotometer by following the liberation of p-nitrophenolate ion (1 M $\varepsilon, \mathrm{pH}$ 
9.4, $17,600 \mathrm{M}^{-1} \mathrm{~cm}^{-1}$ ) at $410 \mathrm{~nm}$. Standard conditions were $50 \mathrm{mM}$ AMPOL buffer, $\mathrm{pH}$ 9.4, containing $2 \mathrm{mM} \mathrm{MgCl} 2$ and $1 \mathrm{mM}$ pNPP in a final volume of $1.0 \mathrm{~mL}$. The reaction was initiated by the addition of the enzyme and stopped with $1.0 \mathrm{~mL}$ of $1.0 \mathrm{M}$ $\mathrm{NaOH}$ at appropriate time intervals. For ATPase, the activity was also assayed discontinuously by measuring the amount of inorganic phosphate liberated, adjusting the assay medium to a final volume of $1.0 \mathrm{~mL}$. The reaction was initiated by the addition of the enzyme, stopped with $0.5 \mathrm{~mL}$ of cold $30 \%$ trichloroacetic acid at appropriate time intervals. The reaction mixtures were centrifuged at 4,000 $\mathrm{g}$ prior to phosphate determi-

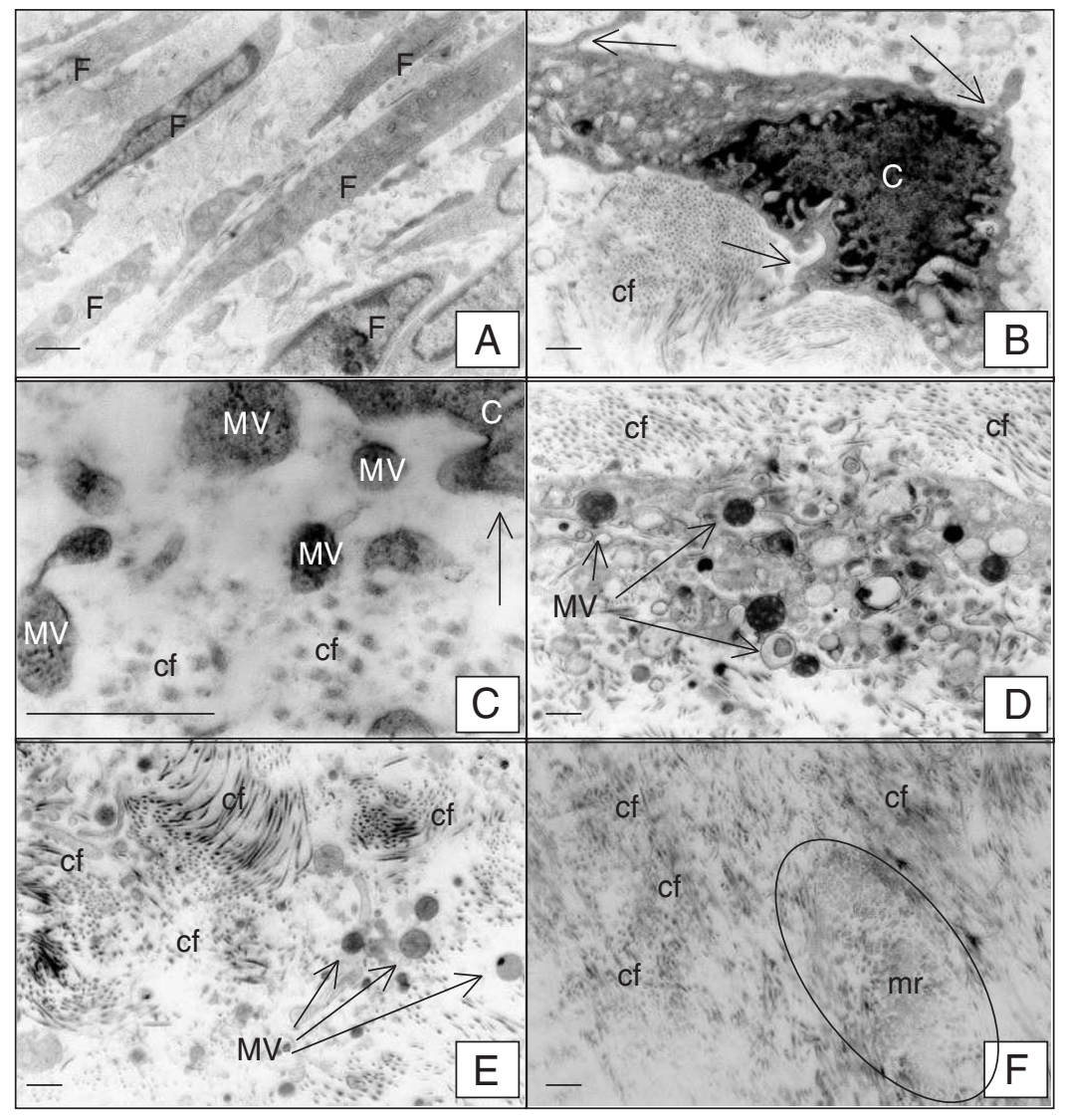

Figure 1. Mineralization was induced by implanting demineralized rat diaphyseal bone matrix into the dorsal subcutaneous tissue of young male Wistar rats. Fourteen days postimplantation the tissue was removed and processed for electron microscopy as described in Material and Methods. A, Fibroblast "F"; $B$, chondrocyte "C"; $B$ and $C$ details of matrix vesicles (MV) budding from chondrocyte membrane (arrows); $D$ and $E$, extracellular MV and collagen fibers "cf"; $F$, stage of advanced mineralization ("mr" indicates mineralization region previously occupied by hypertrophic chondrocytes). Bars correspond to $500 \mathrm{~nm}$. nation. Standard assay conditions were 50 mM AMPOL buffer, $\mathrm{pH} 9.4$, containing 2 $\mathrm{mM} \mathrm{MgCl}_{2}$ and $2 \mathrm{mM}$ ATP. For $\mathrm{PP}_{\mathrm{i}}$ ase activity assays, standard conditions were 50 $\mathrm{mM}$ Tris/ $\mathrm{HCl}$ buffer, $\mathrm{pH} 8.0$, containing 2 $\mathrm{mM} \mathrm{MgCl}_{2}$ and $2 \mathrm{mM}$ sodium pyrophosphate, and processes performed as described for ATPase activity.

All determinations were carried out in triplicate and the initial velocities were constant for at least 90 min provided that less than $5 \%$ of the substrate was hydrolyzed. Controls without added enzyme were included in each experiment to account for the non-enzymatic hydrolysis of substrate.

\section{Determination of kinetic parameters}

Maximum velocity, catalytic constant $\left(k_{\text {cat }}\right)$, apparent dissociation constant $\left(K_{0.5}\right)$, and Hill coefficient obtained from substrate hydrolysis were calculated using the software described by Leone et al. (27). Data are reported as the mean of triplicate measurements of three different enzyme preparations, which was considered to be statistically significant at $\mathrm{P} \leq 0.05$.

\section{Statistical analysis}

Kinetic data were submitted to analysis of variance in a completely randomized design and differences between means were verified by the Tukey test $(\mathrm{P}<0.05)$.

\section{Results and Discussion}

Ectopic bone formation can be reproduced experimentally by implantation of demineralized bone matrix (8) or by implantation of morphogenic proteins at ectopic sites (10). This process permits clear visualization of a sequence of mineral nucleating events in the osteoid, in the absence of an established mineralizing front (28). In particular, implantation of decalcified bone matrix triggers the cascade leading to endo- 
chondral bone formation. The histological profile of the tissue 14 days after implantation of demineralized bone indicates the presence of fibroblasts and chondrocytes. The 14-day endpoint was chosen because TNAP activity of the implant was maximal at this stage (9). By means of electron microscopy, fibroblasts (Figure 1A), hypertrophic chondrocytes (Figure 1B), osteoblasts can be identified in the specimens in agreement with previous studies $(8,9,11,28,29)$. The presence of fibroblasts has been considered a characteristic of the initial stages of the calcification process while chondrocytes are characteristic of later stages $(8,9,14)$. The histological profile of the implanted demineralized bone matrix 14 days after implantation of bone matrix shows typical features of the later stage of endochondral osteogenesis, namely bone and cartilage (Figure 1F).

We found MVs budding from chondrocytes (see Figure 1C and E) and the presence of collagen fibers in the extracellular matrix (Figure 1E). Many chondrocyte-derived MVs appeared to serve as nucleation sites for mineralization during induced ectopic osteogenesis as they contained needle-like crystals consistent with hydroxyapatite (Figure 1D and E). These vesicles had a Gaussian size distribution of 150 to $600 \mathrm{~nm}$ with a median of $306 \pm 103 \mathrm{~nm}$ (Figure 2). This median diameter is similar to that reported by us and others during mineralization of epiphyseal cartilage as well as in cultured chondrocytes $(7,30,31)$. This wide size distribution may indicate that more than one type of MV exist. However, it is as yet unknown whether a single cell produces multiple sub-classes of MVs at a specific stage of differentiation or if each cell produces only one class of MV $(30,31)$.

The implants contained high levels of TNAP capable of hydrolyzing pNPP, ATP and $\mathrm{PP}_{\mathrm{i}}$ (Table 1). Since TNAP is not the only enzyme present in the membrane $(4,13$, 14,19,32-37) the enzymatic studies were carried out using isolated membrane-bound, polidocanol-solubilized and also PIPLC-released TNAP. There were significant differences $(\mathrm{P}<0.05)$ in terms of substrate utilization by the different purified TNAP preparations. The PIPLC-solubilized enzyme displays approximately a 700 -fold increase in

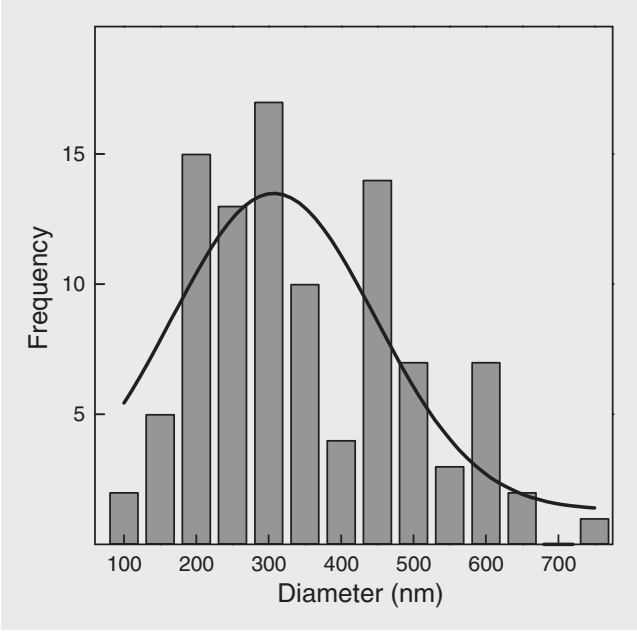

Figure 2. Gaussian distribution of the diameter of 100 matrix vesicles determined from electron micrographs of 14-day-old mineralized implants.

Table 1. Kinetic parameters of tissue-nonspecific alkaline phosphatase present in the matrix vesicles acting on different substrates.

\begin{tabular}{|c|c|c|c|c|c|c|c|c|c|c|}
\hline \multirow[t]{2}{*}{ Substrate } & \multirow[t]{2}{*}{$\mathrm{pH}$} & \multicolumn{2}{|c|}{ Membrane fraction } & \multirow{2}{*}{$\begin{array}{l}k_{\text {cat }} / K_{m} \\
\left(\mathrm{M}^{-1} \mathrm{~s}^{-1}\right)\end{array}$} & \multicolumn{2}{|c|}{ Polidocanol-solubilized } & \multirow{2}{*}{$\begin{array}{l}k_{\text {cat }} / K_{m} \\
\left(\mathrm{M}^{-1} \mathrm{~s}^{-1}\right)\end{array}$} & \multicolumn{2}{|c|}{ PIPLC-solubilized } & \multirow{2}{*}{$\begin{array}{l}k_{\text {cat }} / K_{\mathrm{m}} \\
\left(\mathrm{M}^{-1} \mathrm{~s}^{-1}\right)\end{array}$} \\
\hline & & $k_{\text {cat }}\left(\mathrm{s}^{-1}\right)$ & $K_{m}(\mathrm{M})$ & & $k_{\text {cat }}\left(\mathrm{s}^{-1}\right)$ & $K_{m}(\mathrm{M})$ & & $k_{\text {cat }}\left(\mathrm{s}^{-1}\right)$ & $K_{\mathrm{m}}(\mathrm{M})$ & \\
\hline pNPP & 9.4 & 0.79 & $1.0 \times 10^{-4}$ & $7.3 \times 10^{4}$ & 2.21 & $4.1 \times 10^{-5}$ & $5.5 \times 10^{4}$ & $550.2^{*}$ & $7.0 \times 10^{-5}$ & $7.9 \times 10^{6}$ \\
\hline ATP & 9.4 & 1.23 & $1.5 \times 10^{-4}$ & $8.2 \times 10^{3}$ & 0.65 & $0.9 \times 10^{-5}$ & $7.2 \times 10^{3}$ & $59.2^{*}$ & $1.3 \times 10^{-4}$ & $4.6 \times 10^{5}$ \\
\hline $\mathrm{PP}_{\mathrm{i}}$ & 8.0 & 0.23 & $1.4 \times 10^{-3}$ & $1.6 \times 10^{2}$ & 0.52 & $1.1 \times 10^{-3}$ & $4.7 \times 10^{2}$ & $87.5^{*}$ & $9.8 \times 10^{-4}$ & $8.9 \times 10^{4}$ \\
\hline
\end{tabular}

Preparations were buffered with $50 \mathrm{mM}$ 2-amino-2-methyl-propan-1-ol containing different concentrations of substrates as described in Material and Methods. Data are reported as the mean of triplicate measurement of three different enzyme preparations. PIPLC = phosphatidylinositolspecific phospholipase C; $k_{\text {cat }}=$ catalytic constant; $K_{\mathrm{m}}=$ dissociation constant; pNPP $=$ p-nitrophenylphosphate; ATP $=$ adenosine-5'-triphosphate; $\mathrm{PP}_{\mathrm{i}}=$ pyrophosphate.

${ }^{*} \mathrm{P}<0.05$ compared to membrane fraction (Tukey test). 
$k_{\text {cat }}$ for pNPP, 48-fold for ATP and 380-fold for $\mathrm{PP}_{\mathrm{i}}$ with respect to the membrane-bound enzyme. However, comparing the polidocanol-solubilized enzyme to the membranebound enzyme the values for $k_{\text {cat }}$ barely changed and even decreased as in the case of ATP. Furthermore, while the enzymatic efficiency $\left(k_{\mathrm{cat}} / K_{\mathrm{m}}\right)$ remained comparable between the polidocanol-solubilized and the membrane-bound enzyme for all three substrates, the value for $k_{\mathrm{cat}} / K_{\mathrm{m}}$ for the PIPLCsolubilized enzyme $(\mathrm{P}<0.05)$ increased approximately 108-, 56-, and 556-fold for pNPP, ATP and $\mathrm{PP}_{\mathrm{i}}$, respectively, compared to the membrane-bound enzyme. Since TNAP is anchored to the membrane by a phosphatidylinositol moiety $(13,33)$, this suggests that the catalytic efficiency of TNAP is strongly affected by diacylglycerol or by molecules binding to it.

These data are relevant to interpreting studies aimed at understanding the functional consequences of mutations in TNAP known to cause hypophosphatasia $(36,38$, $39)$. We recently reported that several hypophosphatasia mutations in mice displayed selectivity towards $\mathrm{PP}_{\mathrm{i}}$ versus pyridoxal-5'phosphate, another natural substrate of the enzyme, and that this selectivity could explain in part the variable expressivity of epileptic seizures in patients harboring those mutations (36). We have also recently obtained experimental evidence to support the previous contention that the primary role of TNAP in bone is to hydrolyze $\mathrm{PP}_{\mathrm{i}}$, a potent inhibitor of hydroxyapatite deposition, thus helping to restrict the pool of extracellular $\mathrm{PP}_{\mathrm{i}}$ and ensure proper mineralization $(24,40)$. The main source of $\mathrm{PP}_{\mathrm{i}}$ at the level of MVs is the pyrophosphohydrolase activity of NPP1 that converts extracellular ATP into AMP and $\mathrm{PP}_{\mathrm{i}}$. However, TNAP, which co-localizes with NPP1 on the MVs, hydrolyzes
ATP to produce ADP and $\mathrm{P}_{\mathrm{i}}$ while being affected allosterically by ATP (33) and being subjected to competitive inhibition by the product of this reaction, i.e., $\mathrm{P}_{\mathrm{i}}$. In turn, both ADP and AMP can also serve as substrates of TNAP. Thus, the relative concentrations of ATP, ADP, AMP, $\mathrm{PP}_{\mathrm{i}}$, and $\mathrm{P}_{\mathrm{i}}$ will have an influence on TNAP function. Our data suggest that the location of TNAP on the membrane of MVs may play a role in determining substrate selectivity in this micro-compartment. These data also suggest that assays of TNAP mutants bound to MVs or to liposome-based systems may be more biologically relevant than assays done on solubilized enzyme preparations.

We have shown here that the ectopic mineralization process induced by ectopic implantation of demineralized bone matrix occurs via an MV-mediated mechanism analogous to that of endochondral ossification. The MVs contain high levels of TNAP able to function as ATPase and pyrophosphatase, although the kinetics towards the substrates is greatly affected by the presence of diacylglycerol moieties and other cell membrane components. It is still unclear if the size and localization of the MVs may further affect the kinetic properties of TNAP but studies in this regard should further our understanding of the biological role of this enzyme during bone mineralization and better explain the abnormalities caused by different hypophosphatasia mutations.

\section{Acknowledgments}

The authors thank Mrs. Priscila Cerviglieri for reviewing the text. We also thank Maria Dolores S. Ferreira, Faculdade de Medicina de Ribeirão Preto, USP, for the electron microscopy work. 


\section{References}

1. Blumenthal NC (1989). Mechanism of inhibition and calcification. Clinical Orthopaedics and Related Research, 247: 279-289.

2. Poole AR, Mitsui $Y$, Hinek A et al. (1989). Cartilage macromolecules and the calcification of cartilage matrix. Anatomical Record, 224: 167-179.

3. Freemont AJ (1993). Basic bone cell biology. International Journal of Experimental Pathology, 74: 411-416.

4. Anderson HC (1995). Molecular biology of matrix vesicles. Clinical Orthopaedics and Related Research, 314: 266-280.

5. Hsu HHT \& Anderson HC (1995). A role for ATPase in the mechanisms of ATP-dependent $\mathrm{Ca}$ and phosphate deposition by isolated rachitic matrix vesicles. International Journal of Biochemistry, 27: 1349-1356.

6. Boyan BD, Schwartz Z \& Boskey AL (2000). The importance of mineral in bone and mineral research. Bone, 27: 341-342.

7. Kirsch T, Wang W \& Pfander D (2003). Functional differences between growth plate apoptotic bodies and matrix vesicles. Journal of Bone and Mineral Research, 18: 1872-1881.

8. Reddi AH \& Huggins CB (1972). Biochemical sequences in the transformation of normal fibroblasts in adolescent rats. Proceedings of the National Academy of Sciences, USA, 69: 1601-1605.

9. Curti C, Pizauro JM, Rossinholi G et al. (1986). Isolation and kinetic properties of an alkaline phosphatase from rat bone matrix-induced cartilage. Cellular and Molecular Biology, 32: 55-62.

10. Urist MR, Iwata H, Ceccotti PL et al. (1973). Bone morphogenesis in implants of insoluble bone gelatin. Proceedings of the National Academy of Sciences, USA, 70: 3511-3515.

11. Reddi AH (2000). Initiation and promotion of endochondral bone formation by bone morphogenetic proteins: potential implications for avian tibial dyschondroplasia. Poultry Science, 9: 978-981.

12. Ciancaglini P, Pizauro JM, Rezende AA et al. (1990). Solubilization of membrane-bound matrix-induced alkaline phosphatase with polyoxyethylene 9-lauryl ether (polidocanol): purification and metalloenzyme properties. International Journal of Biochemistry, 22: 385392.

13. Pizauro JM, Ciancaglini P \& Leone FA (1995). Characterization of the phosphatidylinositol-specific phospholipase C-released form of rat osseous plate alkaline phosphatase and its possible significance on endochondral ossification. Molecular and Cellular Biochemistry, 152: 121-129.

14. Leone FA, Pizauro JM \& Ciancaglini P (1997). Rat osseous plate alkaline phosphatase: a search for its role in biomineralization. Trends in Comparative Biochemistry and Physiology, 3: 57-73.

15. Camolezi FL, Daghastanli KRP, Magalhães PP et al. (2002). Construction of an alkaline phosphatase-liposome system: a tool for biomineralization study. International Journal of Biochemistry and Cell Biology, 34: 1091-1101.

16. Ierardi DF, Pizauro JM \& Ciancaglini P (2002). Erythrocyte ghost cell-alkaline phosphatase: construction and characterization of a vesicular system for use in biomineralization studies. Biochimica et Biophysica Acta, 1567: 183-192.

17. Ali SY, Sajdera SW \& Anderson HC (1970). Isolation and characterization of calcifying matrix vesicles from epiphyseal cartilage. Proceedings of the National Academy of Sciences, USA, 67: 15131520.

18. Ali SY, Anderson HC \& Sajdera SW (1971). Enzymic and electronmicroscopic analysis of extracellular matrix vesicles associated with calcification in cartilage. Biochemical Journal, 122: 1-56.
19. Anderson HC (2003). Matrix vesicles and calcification. Current Rheumatology Reports, 5: 222-226.

20. Ali SY \& Evans $L$ (1973). The uptake of ${ }^{45} \mathrm{Ca}$ ions by matrix vesicles isolated from calcifying cartilage. Biochemical Journal, 134: 647650.

21. Schwartz Z, Schlader DL, Swain LD et al. (1998). Direct effects of 1,25-dihydroxyvitamin $D_{3}$ and 24,25-dihydroxyvitamin $D 3$ on growth zone and resting zone chondrocyte membrane alkaline phosphatase and phospholipase-A2 specific activities. Endocrinology, 1: 28782884.

22. Hoshi K \& Ozawa H (2000). Matrix vesicle calcification in bones of adult rats. Calcified Tissue International, 66: 430-434.

23. Rezende AA, Pizauro JM, Ciancaglini P et al. (1994). Phosphodiesterase activity is a novel property of alkaline phosphatase from osseous plate. Biochemical Journal, 301: 517-522.

24. Hessle L, Johnsson KA, Anderson HC et al. (2002). Tissue-nonspecific alkaline phosphatase and plasma cell membrane glycoprotein1 are central antagonistic regulators of bone mineralization. Proceedings of the National Academy of Sciences, USA, 99: 94459449.

25. Anderson HC, Hsu HHT, Morris DC et al. (1997). Matrix vesicles in osteomalacic hypophosphatasia bone contain apatite-like mineral crystals. American Journal of Pathology, 151: 1555-1561.

26. Anderson HC, Sipe JB, Hessle L et al. (2004). Impaired calcification around matrix vesicles of growth plate and bone in alkaline phosphatase-deficient mice. American Journal of Pathology, 164: 841847.

27. Leone FA, Degreve L \& Baranauskas JA (1992). Sigraf: A versatile computer-program for fitting enzyme kinetic data. Biochemical Education, 20: 94-96.

28. Reddi AH \& Anderson WA (1976). Collagenous bone matrix-induced endochondral ossification and hemopoiesis. Journal of Cell Biology, 69: 557-572.

29. Urist MR, Mikulski A \& Lietze A (1979). Solubilized and insolubilized bone morphogenetic protein. Proceedings of the National Academy of Sciences, USA, 76: 1828-1832.

30. Hsu HHT \& Anderson HC (1978). Calcification of isolated matrix vesicles and reconstituted vesicles from fetal bovine cartilage. Proceedings of the National Academy of Sciences, USA, 75: 38053808.

31. Sela J, Gross UM, Kohavi D et al. (2000). Primary mineralization at the surfaces of implants. Critical Reviews in Oral Biology and Medicine, 11: 423-436.

32. Hsu HHT \& Anderson HC (1996). Evidence of the presence of a specific ATPase responsible for ATP-initiated calcification by matrix vesicles isolated from cartilage and bone. Journal of Biological Chemistry, 271: 26383-26388.

33. Pizauro JM, Demenis MA, Ciancaglini P et al. (1998). Kinetic characterization of a membrane-specific ATPase from rat osseous plate and its possible significance on endochondral ossification. Biochimica et Biophysica Acta, 1368: 108-114.

34. Demenis MA \& Leone FA (2000). Kinetic characteristics of ATP hydrolysis by a detergent-solubilized alkaline phosphatase from rat osseous plate. IUBMB Life, 49: 113-119.

35. Johnson KA, Wennberg C, Hessle L et al. (2000). Osteoblast tissuenonspecific alkaline phosphatase antagonizes and regulates PC-1. American Journal of Physiology, 279: R1365-R1377.

36. Mauro S, Manes T, Hessle L et al. (2002). Kinetic characterization of 
hypophosphatasia mutations with physiological substrates. Journal of Bone and Mineral Research, 17: 1383-1391.

37. Demenis MA, Furriel RP \& Leone FA (2003). Characterization of an ectonucleoside triphosphate diphosphohydrolase 1 activity in alkaline phosphatase-depleted rat osseous plate membranes: possible functional involvement in the calcification process. Biochimica et Biophysica Acta, 1646: 216-225.

38. Henthorn PS \& Whyte MP (1992). Missense mutations of the tissuenonspecific alkaline phosphatase gene in hypophosphatasia. Clini- cal Chemistry, 38: 2501-2505.

39. Zurutuza L, Muller F, Gibrat JF et al. (1999). Correlations of genotype and phenotype in hypophosphatasia. Human Molecular Genetics, 8: 1039-1046.

40. Harmey D, Hessle L, Narisawa S et al. (2004). Concerted regulation of inorganic pyrophosphate and osteopontin by Akp2, Enpp1 and Ank. An integrated model of the pathogenesis of mineralization disorders. American Journal of Pathology, 164: 1199-1209. 